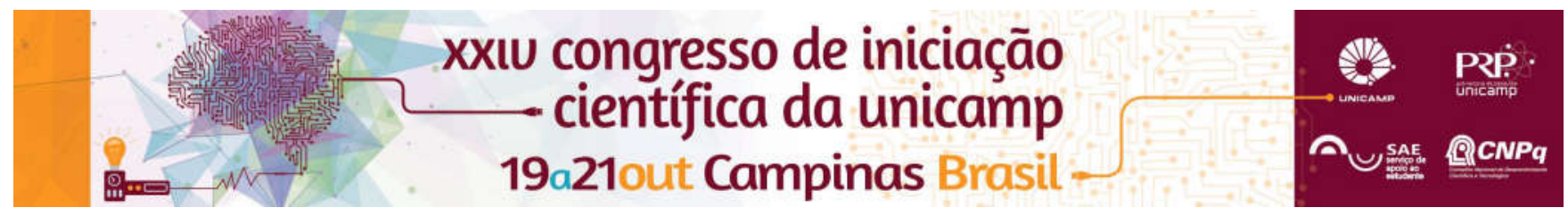

\title{
The resources of polyphonic simulation in the works of Luciano Berio and J.S.Bach
}

\section{Vinicius Cesar de Oliveira}

\begin{abstract}
This research aims to estudy the compositional elements that Bach used to create your "polyphonic melodies" presents in his partitas for solo violin, trace relationship with latent polyphony of Berio's Sequenze; and check what were the compositional influences that Bach's polyphonic writing had on the Berio's polyphonic ideal.

For that were developed three steps; Melodic analysis of Bach's Chaconne BWV 1004; Melodic analysis of Berio's Sequenza I; Research and comparative study between the writing of the two composers.
\end{abstract}

\section{Key words: \\ Lantent Polyphony, Bach, Berio}

\section{Introduction}

One of the clearest evolutionary aspects of music in history is your directionality to a growing complexity of events that occurring at the same time. Thus, from the sound aspects that the advent of his writing provides him since the early days of musical writing, the music walked the path of simultaneities.

Its fact that even before monodies the listening is invited to hear polyphonic plans. Thereby, we can define polyphony at first not only as existence of different melodic layers overlapping, but the existence of plans that show in parallel and these plans are a continuity timeline. Thus, any rupture in the continuity of these plans creates an expectation of return or his end.

Therefore, polyphony is a game between two or more continuous field overlapping that do not establish relationship with each other, but develop an interaction through dialogues. To build these continuous plans, Berio see in Bach's partitas for solo violin and cello sonatas the reference to build the latent polyphony of your Sequenze.

\section{Results and Discussion}

The process of studying of Bach's Chaconne and Berio's Sequenza I consisted of melodic analysis. It was taken as theoretical support the principles of harmony, counterpoint and voice leading, like this allowing the decomposition of the pieces in four voices. With these processes of analysis was possible to see the polyphonic relationship that was hide in the texture in each work and from this point to conduct a comparative study looking common and divergent aspects that composers have used to create a polyphonic listening in a single melodic line.

The first aspect that we can highlight is the heights, where the two composers divide all the melodic range in registers low, medium and high, causing several distinct and simultaneous plans that are differentiated by their location inside the tessitura.

Another important factor in the melodic structure in order to simulate polyphony is how elements are articulate and evolved gradually, thus occurring breaks of continuous spaces giving rise in side of arpeggios melodic line that coexist and overlap each other.

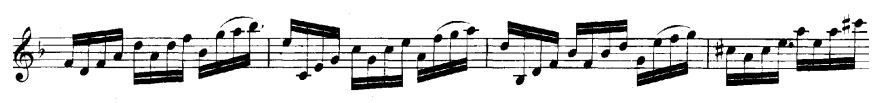

Image 1. Excerpt of latent polyphony in Chaconne, performed by breaks of continuous space

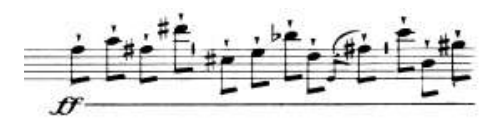

Figura 2. Procedure used by Berio, suchlike Bach's example.

However, Berio uses a third process of polyphonic simulation that is the articulation of differentiation abrupt of elements and the increase of instrumental activity (modes of attack, dynamics and extreme leaps), in other words, Berio's concept of density of melodic path. This process creates tension in the whole work and consequently generates several listening fields simultaneous which contributes to a latent polyphony.

\section{Conclusions}

With all the analyzes and studies accomplished in this research it could be effectively concluded that Berio makes use of inherited aspects of tradition, more specifically coming from Bach. Division and distinction of melodic range through delimited registers and articulation and gradual evolution of the elements generating spaces breaks. However Berio takes the last consequences his simulated writing polyphony when not done continuities and continuities breaks, but abruptly distinguish elements, creating a continuous field of latent layers that has the potential to happen, but it does not happen, thus going beyond the Bach's written.

\section{Acknowledgement}

To FAPESP, for the fomentation that enables fulfillment of this work.

To my advisor, Profa. Dra. Denise H. L. Garcia, for support and trust.

BERIO, L. Entrevista sobre a música contemporânea (realizada por Rossana Dalmonte). Rio de Janeiro: Civilização Brasileira, 1996

ENTREVISTA com Flo Menezes sobre Luciano Berio e suas Sequenze. Produção de Raimo Benedetti. São Paulo: 2010. 1 vídeo de (39min)

FERRAZ, S. Diferença e repetição: A polifonia simulada na Sequenza VII para oboé, de Luciano Berio. 1989.

Tecnica estendida e escrita polifônica em Luciano Berio:Sequenza XIV. São Paulo: Editora Unesp, 2016.

SCHOENBERG, A. Exercícios preliminares em contraponto. Tradução de Eduardo Seincman. Via Lettera. São Paulo: 2001. 